\title{
La desaparición forzada como hecho ilícito permanente en la jurisprudencia de la Corte Interamericana de Derechos Humanos
}

\author{
Pietro Sferrazza Taibi*
}

\begin{abstract}
RESUMEN
El objetivo de este trabajo consiste en explicar el carácter permanente de la desaparición forzada de personas como becho internacionalmente ilícito y las repercusiones de esta característica en la activación de la competencia temporal o ratione temporis de la Corte Interamericana de Derechos Humanos. Para tal efecto se defenderá que la desaparición forzada es un becho ilicito internacional permanente, y sobre la base de esta defensa se analizará críticamente la evolución de la jurisprudencia de la Corte Interamericana acerca del problema de la competencia temporal respecto de este ilicito.
\end{abstract}

Desaparición forzada - Corte Interamericana de Derechos Humanos competencia temporal

\section{Enforced disappearance as a continuous wrongful act in Inter-American Court of Human Rights case law}

\begin{abstract}
The aim of this paper is to explain the permanent nature of enforced disappearance as internationally wrongful act and the impact of this feature on the Inter-American Court of Human Rights temporal jurisdiction or ratione temporis. To this end, it will defend that enforced disappearance is a permanent internationally wrongful act and, on the basis of this defense, it will critically analyze the evolving jurisprudence of the Inter-American Court on temporal jurisdiction over such illicit.
\end{abstract}

Enforced disappearance - Inter-American Court of Human Rights temporal jurisdiction

\footnotetext{
* Licenciado en Ciencias Jurídicas, Universidad de Valparaíso. Doctor en Estudios Avanzados en Derechos Humanos, Universidad Carlos III de Madrid, España. Profesor de Derecho Internacional Público, Universidad Andrés Bello, Viña del Mar. Correo electrónico: pietrosferrazza@gmail.com.

Artículo recibido el 5.7.2016 y aceptado para su publicación en este número el 5.1.2018.
} 


\section{INTRODUCCIÓN $* *$}

S i bien con relativa frecuencia se afirma que la desaparición forzada es un hecho de carácter permanente, el estudio de esta característica desde la óptica de la teoría de la responsabilidad internacional del Estado no ha sido muy abordado por la doctrina. Tampoco se ha estudiado en profundidad las repercusiones que esta caracterización de la desaparición forzada han tenido en la activación de la competencia temporal de los tribunales y órganos internacionales de derechos humanos.

El presente estudio se propone explicar las razones por las que es plausible considerar la desaparición forzada como un hecho internacional ilícito permanente. Sobre la base de dicha propuesta, se abordará un análisis crítico de la jurisprudencia de la Corte Interamericana de Derechos Humanos (en adelante, Corte IDH) respecto de su competencia temporal o ratione temporis en materia de desapariciones. Para el cumplimiento de este dúplice cometido, el trabajo se dividirá en dos partes. En la primera de ellas se reflexionará acerca de la noción de hecho ilícito internacional permanente. Teniendo presente esta noción, se defenderá que la desaparición es un hecho ilícito internacional de esa índole, no solo porque los tratados internacionales lo han afirmado explícitamente, sino porque la conceptualización de la desaparición se condice la caracterización de ese tipo de hechos. En la segunda sección del trabajo, en cambio, se analizará de qué manera la Corte IDH ha abordado el problema de su competencia temporal respecto de las desapariciones forzadas, especialmente respecto de aquellas que se iniciaron antes de la entrada en vigor de la Convención Americana sobre Derechos Humanos (en adelante, $\mathrm{CADH})^{1}$ o del reconocimiento de competencia de este tribunal por los Estados partes de dicha Convención.

\section{LA DESAPARICIÓN FORZADA COMO UN HECHO ILÍCITO INTERNACIONAL PERMANENTE}

La noción de hecho internacional ilícito permanente ha sido desarrollada en el ámbito de la responsabilidad internacional del Estado, una de las materias más importantes del Derecho internacional público ${ }^{2}$. La elaboración de un concepto unívoco y general de la responsabilidad internacional es una tarea compleja, porque debido a su generalidad se trata de una noción que se relaciona con un sinnúmero de tópicos del Derecho internacional.

\footnotetext{
** Agradezco los comentarios de Nicole Selamé, María Isabel Puerto y Francisca Oyarzún a una versión preliminar de este artículo.

${ }^{1}$ Convención Americana sobre Derechos Humanos. Aprobada en San José de Costa Rica, 22 de noviembre de 1969, entrada en vigor el 18 de julio de 1979.

2 Según Cançado Trindade, A. A., International Law for Humankind. Towards a New Jus Gentium, $2^{\mathrm{a}} \mathrm{ed}$. revisada, Brill-Nijhoff, Leiden-Boston, 2010, p. 453, la responsabilidad internacional representa a complex, truly central and fundamental chapter of Public International Law as a whole [un capítulo complejo, realmente central y fundamental del Derecho internacional público en su conjunto].
} 
Mariño Menéndez la define como "un comportamiento determinado, atribuido a un sujeto de Derecho Internacional, [...] calificado por este ordenamiento como 'lesivo' para derechos o intereses de terceros sujetos y, por ello, [...] considerado un hecho jurídico al cual el Derecho Internacional vincula consecuencias determinadas: dar origen a un conjunto de nuevas relaciones jurídicas ('de responsabilidad') entre el sujeto al que se atribuya el hecho y el sujeto o sujetos injustamente perjudicados por el comportamiento de aquel" 3 . A su vez, Stern argumenta que la responsabilidad internacional se define tradicionalmente como el conjunto de obligaciones que un sujeto internacional debe cumplir como consecuencia de una acción u omisión que le es imputable ${ }^{4}$.

El principal instrumento normativo que regula la responsabilidad internacional del Estado es el Proyecto de artículos sobre Responsabilidad del Estado por Hechos Internacionalmente Ilícitos (en adelante, PARIEHII) elaborado en el seno de la Comisión de Derecho Internacional (en adelante, CDI) de Naciones Unidas ${ }^{5}$. Si bien detallar minuciosamente el trabajo de la CDI en la codificación de la responsabilidad internacional del Estado requeriría un estudio histórico-normativo que escapa del objeto del presente trabajo, es factible recordar que el Proyecto se aprobó en primera lectura en $1996^{6}$ y que la versión definitiva fue aprobada en segunda lectura en 2001. Ese mismo año la Asamblea General de Naciones Unidas (en adelante, AG) tomó nota de su aprobación mediante una resolución ${ }^{7}$. El articulado del Proyecto viene acompañado por un conjunto de Comentarios que constituyen una valiosa herramienta para su interpretación ${ }^{8}$.

El corazón de la teoría de la responsabilidad internacional del Estado es la noción de hecho internacionalmente ilícito, esto es, la acción u omisión imputable a un Estado, que comporta la infracción de una obligación internacional vigente para ese Estado9 . Por tanto, el hecho internacionalmente ilícito está integrado por dos elementos: la ilicitud y el comportamiento imputable ${ }^{10}$. La ilicitud es la disconformidad, violación o vulne-

${ }^{3}$ Mariño Menéndez, F., Derecho Internacional Público. Parte General. $4^{\mathrm{a}}$ ed., Trotta, Madrid, 2005, p. 473.

${ }^{4}$ Stern, B., "The Elements of an Internationally Wrongful Act", en Crawford, J./Pellet, A./Olleson, S. (eds.), The Law of International Responsibility, Oxford University Press, Oxford, 2010, p. 194.

5 CDI, Proyecto de artículos sobre responsabilidad internacional del Estado, en CDI, Informe de la Comisión de Derecho Internacional, $53^{\circ}$ período de sesiones (23 de abril a $1^{\circ}$ de junio y 2 de julio a 10 de agosto de 2001), A/56/10, pp. 21-405. El Proyecto y sus Comentarios han sido traducidos al castellano: vid. Crawford, J., Los artículos de la Comisión de Derecho Internacional sobre la responsabilidad Internacional del estado. Introducción, texto y comentarios. Introducción y apéndices traducidos por L. Fonseca, bajo la supervisión de C. Espósito. Dykinson, Madrid, 2004.

${ }^{6}$ CDI, "Draft articles on State responsibility. 1. Text of the Draft Articles Provisionally Adopted by the Commission on First Reading", Yearbook of the International Law Commission, 1996, vol. II (2), pp. 58-73.

${ }^{7}$ AG, Responsabilidad del Estado por Hechos Internacionalmente Ilícitos, res. 56/83, 12 de diciembre de 2001. Para un resumen de los trabajos preparatorios del PARIEHII, vid. Mariño Menéndez, op. cit., pp. 474-475.

${ }^{8}$ Pellet, A., "The ILC'S Articles on State Responsibility for Internationally Wrongful Acts and Related Texts”, en Crawford/Pellet/Olleson, op. cit., p. 84.

${ }^{9}$ PARIEHII, cit., art. 2.

${ }^{10}$ Así lo sostuvo también la Corte Internacional de Justicia, United States Diplomatic and Consular Staff in Tehran, judgment, 24 de mayo de 1980, I.C.J. Reports, 1980, párr. 56. 
ración de una obligación internacional, que se genera por un hecho de un Estado ${ }^{11}$. Por su parte, la imputabilidad o atribución es una operación jurídica que tiene por objeto determinar si el comportamiento de una persona física o jurídica puede considerarse un acto del Estado ${ }^{12}$.

Aclaradas estas nociones generales, se debe mencionar que el hecho internacionalmente ilícito puede ser clasificado en atención a la extensión temporal de la violación de una obligación internacional. Esta clasificación distingue entre hecho instantáneo, hecho permanente y hecho compuesto. Para los efectos de este artículo interesa sobremanera comprender la noción de hecho ilícito permanente, que puede entenderse como una violación continua de una obligación internacional mediante la comisión de una acción u omisión que se prolonga en el tiempo ${ }^{13}$. De conformidad con el artículo 14 (1) del PARIEHII, "la violación de una obligación internacional mediante un hecho del Estado que tiene carácter continuo se extiende durante todo el período en el cual el hecho continúa y se mantiene su falta de conformidad con la obligación internacional”. Ejemplos de hechos ilícitos permanentes, entre otros, son la ocupación ilegal de un territorio o el mantenimiento en el ordenamiento jurídico nacional de una legislación contraria a las obligaciones internacionales del Estado respectivo ${ }^{14}$.

De esa manera, el hecho ilícito permanente se diferencia del hecho ilícito instantáneo o consumado, pues este último "tiene lugar en el momento en que se produce el hecho, aunque sus efectos perduren" ${ }^{15}$. La calificación de un hecho ilícito como permanente o instantáneo dependerá del contenido de la norma primaria y en la práctica no siempre será fácil diferenciarlos ${ }^{16}$. Al respecto, es interesante revisar algunos criterios propuestos por Pauwelin para facilitar la tarea de diferenciar ambos hechos en un caso práctico; a saber: 1) centrar la atención en el contenido de la obligación internacional y no en las características del acto; 2) valorar si el cese del ilícito es fácticamente procedente como una medida de reparación, porque el cese solo puede proceder frente a un hecho ilícito

11 PARIEHII, cit., art. 12: "hay violación de una obligación internacional por un Estado cuando un hecho de ese Estado no está en conformidad con lo que de él exige esa obligación, sea cual fuere el origen o la naturaleza de esa obligación”.

${ }^{12}$ Cfr. Condorelli, L./Kress, C., "The Rules of Attribution: General Considerations”, en Crawford/Pellet/ Olleson, op. cit., p. 221; Mariño Menéndez, op. cit., pp. 478-479.

13 Salmon, J. "Duration of the Breach", en Crawford/Pellet/Olleson, op. cit., p. 386.

${ }^{14}$ PARIEHII, cit., art. 14, comentario $\mathrm{N}^{\circ} 3$.

15 Ibid., art. 14 (1).

16 Ibid., art. 14, comentario $\mathrm{N}^{\circ}$ 4-5. Las normas primarias son las que establecen las obligaciones de hacer y no hacer a cuyo cumplimiento están obligados los sujetos de Derecho internacional. En cambio, las normas segundarias son las que determinan cuándo se han vulnerado las normas primarias y qué consecuencias se derivan de dicho incumplimiento. El PARIEHII solo se preocupa de codificar las normas secundarias. La codificación de la totalidad de las normas primarias, en efecto, hubiera sido una tarea humanamente imposible. El Relator Ago fue muy perspicaz al darse cuenta de ello durante la redacción del Proyecto y asumió la distinción entre normas primarias y segundarias como un verdadero dogma, persuadiendo a los demás comisionados que los esfuerzos codificadores debían centrarse en las normas segundarias. Vid. David, E., "Primary and Secondary Rules", en Crawford/Pellet/Olleson, op. cit., pp. 28-29. 
continuado; 3) determinar si es aplicable la ficción legal que permite concebir una renovación del hecho día a día ${ }^{17}$.

Uno de los fines de este trabajo consiste en aclarar si la desaparición forzada se puede considerar un hecho internacional ilícito permanente. Antes de discurrir acerca de ese problema, es necesario recordar la definición internacional de la desaparición. De conformidad con la conceptualización más reciente, contenida en el artículo 2 de la Convención internacional para la protección de todas las personas contra las desapariciones forzadas (en adelante, CIPPDF), se entiende por desaparición forzada el "arresto, la detención, el secuestro o cualquier otra forma de privación de libertad que sean obra de agentes del Estado o por personas o grupos de personas que actúan con la autorización, el apoyo o la aquiescencia del Estado, seguida de la negativa a reconocer dicha privación de libertad o del ocultamiento de la suerte o el paradero de la persona desaparecida, sustrayéndola a la protección de la ley"18.

Así, la desaparición forzada está conformada por tres elementos conceptuales y una consecuencia $^{19}$. Los elementos conceptuales son: 1) la privación de libertad; 2) la denegación de información y 3) el sujeto activo. En cambio, la consecuencia que surgiría de la configuración de los elementos anteriores es la sustracción a la protección de la ley ${ }^{20}$.

Con el fin de determinar si la desaparición forzada es un hecho internacionalmente ilícito permanente, es necesario centrar la atención en la denegación de información, esto es, el elemento conceptual que constituye la esencia de la desaparición. Este elemento definitorio, junto con la privación de libertad, es una de las dos conductas constitutivas de la desaparición forzada y consiste en la negativa u ocultamiento de la información sobre la persona desaparecida. Esta conducta puede ser cometida de diferentes maneras, mediante una acción o una omisión ${ }^{21}$. Por ejemplo, la autoridad podría negar la información, evitando reconocer determinados hechos o alegando un desconocimiento respecto de los mismos. También la autoridad podría ocultar intencionadamente la información, esto es, escondiéndola para impedir a los interesados su obtención y conocimiento. Asimismo, la autoridad podría destruir las fuentes de la información o entregar información falsa o tergiversada. En todas estas hipótesis se configura la conducta denegatoria de información ${ }^{22}$.

17 Pauwelin, J., “The Concept of a 'Continuing Violation' of an International Obligation: Selected Problems”, British Yearbook of International Law, vol. 66(1), 1995, pp. 420-421, 430-431, 447-448.

${ }^{18}$ Convención internacional para la protección de todas las personas contra las desapariciones forzadas, aprobada en Nueva York, 20 de diciembre del 2006, entrada en vigor el 23 de diciembre de 2010, UNTS, vol. 2716 , p. 3.

19 Sferrazza Taibi, P., "Desaparición forzada”, Eunomia, No 8, marzo-agosto 2015, p. 164.

${ }^{20}$ Sobre la discusión acerca de la naturaleza de la sustracción a la protección de la ley, Ibíd., pp. 165-166.

21 Andreu-Guzmán, F., "The Draft International Convention on the Protection of All Persons from Forced Disappearance", The Review (International Commission of Jurists), Nº 62-63, septiembre 2001, p. 82.

${ }^{22}$ Id. Cfr. Pérez Solla, M. F., Enforced Disappearances in International Human Rights, McFarland \& Company, Jefferson, 2006, p. 19; Werle, G., Tratado de Derecho Penal Internacional. $2^{\mathrm{a}}$ ed. C. Cárdenas Aravena, J. Couso Salas y M. Gutiérrez Rodríguez (trads.). Tirant lo Blanch, Valencia, 2011, p. 530. Son frecuentes los casos de desapariciones en que la autoridad niega la privación de libertad o entrega una información falsa sobre el destino o paradero de la persona desaparecida. Por ejemplo, en el caso del Tribunal Europeo de 
Es muy importante dilucidar cuál es el contenido exacto de la información que se deniega. Las definiciones internacionales exigen que se proporcione información de la privación de libertad, la suerte y el paradero de la persona desaparecida. Por tanto, las autoridades competentes deben aclarar si la persona cuya información se busca ha sido efectivamente privada de libertad y deben especificar el paradero de esta persona, esto es, la ubicación exacta del lugar en que se encuentra ${ }^{23}$. Respecto de la noción de destino, en principio, se debe informar si la persona está viva o muerta ${ }^{24}$ y en el evento de que haya muerto, debe proporcionarse información de la localización de sus restos mortales ${ }^{25}$.

Debe subrayarse que la denegación de información es el elemento definitorio que diferencia la desaparición forzada de otras figuras afines, así como las detenciones ilegales, la tortura o las ejecuciones extrajudiciales ${ }^{26}$. Esta posición ha sido defendida en la jurisprudencia de la Corte Interamericana de Derechos Humanos (en adelante, Corte $\mathrm{IDH})^{27}$. En efecto, las detenciones ilegales o arbitrarias consisten en privar de libertad a una persona sin una base legal, vulnerándose ciertos derechos humanos o infringiéndose algunas garantías básicas del debido proceso $^{28}$. Por esta razón, se trata de una noción más amplia de la desaparición forzada, en cuanto esta es una categoría más específica de privación de libertad, porque la infracción de derechos o garantías se produce a consecuencia de la ausencia de información respecto de la persona desaparecida.

Por su parte, la desaparición forzada guarda una relación con la tortura, pero se trata de una relación fáctica y no jurídica. En efecto, la ausencia de información de la persona desaparecida configura un contexto fáctico propicio para la comisión de torturas, porque la víctima está aislada de la protección del Derecho al no poder comunicarse

Derechos Humanos, Kurt Vs. Turkey, judgment (15/1997/799/1002), 25 de mayo de 1998, párrs. 16-18, se informó que la persona desaparecida había sido secuestrada por miembros del Partido de Trabajadores del Kurdistán (PKK). En el caso del Comité de Derechos Humanos de Naciones Unidas, Yasoda Sharma Vs. Nepal, comunicación $\mathrm{N}^{\circ}$ 1469/2006, 28 de octubre de 2008, párr. 7.6, se informó que la persona desaparecida se había ahogado en un río mientras escapaba de un operativo de seguridad. En otro caso del mismo Comité, Zobra Madoui Vs. Algeria, comunicación No 1495/2006, 28 de octubre de 2008, párr. 7.4, se comunicó que la persona desaparecida había abandonado su hogar a causa de problemas psiquiátricos.

23 Association for the Prevention of Torture. Incommunicado, Unacknowledged and Secret Detention under International Law [En línea], 2 de marzo de 2006. Disponible en <http://www.apt.ch/en/resources/incommunicadounacknowledged-and-secret-detention-under-international-law-2006/ >. [Consulta: 7 de junio de 2016], p. 10

${ }^{24} I$ d.

${ }^{25}$ Vermeulen, M. L., Enforced Disappearance. Determining State Responsibility under the International Convention for the Protection of All Persons from Enforced Disappearance, Intersentia, Cambridge et al., 2012, p. 177. Cfr. Pérez Solla, op. cit., pp. 13 y 19.

${ }^{26}$ Cfr. Robinson, D., "Defining 'Crimes against Humanity' at the Rome Conference”, American Journal of International Law, 93/1(1999), p. 264; Esposito, A./Gentile, G./Traspasso, M. T., "I crimini contro l' umanitá”, en Lattanzi, G./Monetti, V. (coords.). La Corte Penale Internazionale. Organi-Competenza-ReatiProcesso. Giuffré, Milano, 2006, p. 719.

${ }^{27}$ V. gr., Corte IDH, Gómez Palomino Vs. Perú. Fondo, Reparaciones y Costas. Sentencia de 22 de noviembre de 2005. Serie C No 136 , párr. 103.

${ }^{28}$ Acerca de los criterios definitorios de las detenciones ilegales o arbitrarias, vid. ONU. Folleto Informativo $N^{o}$ 26, El Grupo de Trabajo sobre la Detención Arbitraria. Disponible en <http://www.ohchr.org/Documents/ Publications/FactSheet26sp.pdf>. [Consulta: 25 de noviembre de 2016], punto IV.B. 
con el mundo exterior ${ }^{29}$. Sin embargo, la definición jurídica internacional de la tortura denota que se trata de un hecho distinto, cuya esencia radica en el dolor o sufrimiento físico o mental infligido a la víctima ${ }^{30}$.

Algo similar ocurre entre la desaparición forzada y la ejecución extrajudicial, ya que esta última consiste en la privación de la vida de una persona cometida al margen de un proceso judicial o de la aplicación de una medida legal ${ }^{31}$. Sin embargo, la esencia de la desaparición no estriba en la muerte o presunción de muerte de la persona desaparecida, sino en la ausencia de la información pertinente a su situación, y de hecho puede haber desaparición sin que se constate la muerte de la víctima ${ }^{32}$. Otra cuestión es que en los hechos sea frecuente que la persona desaparecida sea ejecutada extrajudicialmente.

Aclarado lo anterior, será más fácil explicar por qué la desaparición forzada es un hecho ilícito permanente. En efecto, si la denegación de información es la conducta esencial de la desaparición, esta se sigue cometiendo hasta que se obtenga información del destino y paradero de la persona desaparecida. Por esta razón, la desaparición forzada se considera un hecho ilícito permanente. Esta tesis viene confirmada por la mayoría de la doctrina, según esta, la desaparición se prolonga hasta que se produzca la cesación de este ilícito, esto es, al concluir la conducta denegatoria de información. Dicho de otro modo, la desaparición se prolonga hasta que la persona desaparecida reaparece, o sea puesta en libertad, o cuando la autoridad otorga la información concerniente a su privación de libertad, destino y paradero, o cuando se localizan, identifican y entregan sus restos mortales en caso de que haya fallecido ${ }^{33}$.

Por su parte, los principales instrumentos internacionales relativos a la desaparición forzada reafirman el carácter permanente de este grave ilícito. El artículo 17(1) de la Declaración sobre la protección de todas las personas contra las desapariciones forzadas (en adelante, DPPDF) dispone que "todo acto de desaparición forzada será considerado delito permanente mientras sus autores continúen ocultando la suerte y el paradero de

${ }^{29}$ Cfr. Corte IDH. Godinez Cruz Vs. Honduras. Fondo. Sentencia de 20 de enero de 1989. Serie C No 5 , párr. 164; Corte IDH. Fairén Garbi y Solís Corrales Vs. Honduras. Fondo. Sentencia de 15 de marzo de 1989. Serie C N 6 , párr. 149.

${ }^{30}$ Convención contra la Tortura y Otros Tratos o Penas Crueles, Inhumanos o Degradantes, adoptada y abierta a la firma, ratificación y adhesión por la AG en su resolución 39/46, de 10 de diciembre de 1984, entrada en vigor el 26 de junio de 1987, UNTS, vol. 1465, p. 85, art. 1.

${ }^{31}$ Rodley, N./Pollard, M., The Treatment of Prisoners under International Law. $3^{\text {a }}$ ed. Oxford University Press, Oxford, 2009, pp. 252-253; AG, Ejecuciones extrajudiciales, sumarias o arbitrarias. Informe provisional de la situación mundial con respecto a las ejecuciones extrajudiciales, sumarias o arbitrarias presentado por Philip Alston, Relator Especial. A/61/311, 5 de septiembre de 2006, párrs. 34-45.

32 Corte IDH. Heliodoro Portugal Vs. Panamá. Excepciones Preliminares, Fondo, Reparaciones y Costas. Sentencia de 12 de agosto de 2008. Serie C No 186, voto Razonado del juez Sergio García Ramírez, párrs. 15 y 16. Cfr. Rodley/Pollard, op. cit., p. 333.

33 Cfr. Ambos, K., Treatise on International Criminal Law: The Crimes and Sentencing, Volume II, Oxford University Press, Oxford, 2013, p. 112; Kyriakou, N., "Enforced Disappearances in Cyprus: Problems and Prospects of the Case Law of the European Court of Human Rights", European Human Rights Law Review, vol. 2, 2011, pp. 192-193. 
la persona desaparecida y mientras no se hayan esclarecido los hechos" 34 . A su vez, el artículo III de la Convención Interamericana sobre Desapariciones Forzadas (en adelante, CIDF) prescribe que el ilícito "será considerado como continuado o permanente mientras no se establezca el destino o paradero de la víctima"35.

Sin embargo, en la CIPPDF el tratamiento técnico de esta característica es altamente deficiente, ya que no fue regulada expresamente, sino por medio de menciones marginales a propósito de otras materias. Así, en relación con la prescripción el artículo 8 (1)(b) señala que "cada Estado Parte que aplique un régimen de prescripción a la desaparición forzada tomará las medidas necesarias para que el plazo de prescripción de la acción penal: b) Se cuente a partir del momento en que cesa la desaparición forzada, habida cuenta del carácter continuo de este delito". Asimismo, en materia de reparación el artículo 24 (6) obliga a los Estados a la investigación de los hechos "hasta establecer la suerte de la persona desaparecida". Por su parte, el artículo 24 (3) dispone que "cada Estado Parte adoptará todas las medidas apropiadas para la búsqueda, localización y liberación de las personas desaparecidas y, en caso de fallecimiento, para la búsqueda, el respeto y la restitución de sus restos". En conclusión, aunque es criticable el hecho de que la Convención no contenga una regulación clara y explícita para el carácter permanente de la desaparición forzada, una interpretación sistemática y teleológica de sus disposiciones permite concluir que la desaparición es un hecho ilícito permanente ${ }^{36}$.

\section{LA DESAPARICIÓN COMO ILÍCITO PERMANENTE EN LA JURISPRUDENCIA DE LA CORTE IDH}

Para favorecer la claridad de la exposición, esta parte del trabajo será dividida en tres secciones. En primer lugar se hará referencia a la primera etapa jurisprudencial de la Corte IDH sobre la competencia temporal respecto de la desaparición forzada. En la segunda sección se esgrimirán algunas críticas a esta primera etapa, para finalizar con una tercera sección que se dedicará a explicar la evolución de una segunda etapa jurisprudencial que ha abordado el problema de una manera más acorde a la naturaleza de la desaparición.

${ }^{34}$ Declaración sobre la protección de todas las personas contra las desapariciones forzadas, aprobada por la res. 47/133 de la AG, 18 de diciembre de 1992.

${ }^{35}$ Convención Interamericana sobre Desapariciones Forzadas, Belem do Pará, AG/RES 1256 (XXIV-O/94), res. de 9 de junio 1994 de la Asamblea General de la OEA, entrada en vigor el 28 de marzo de 1996.

${ }^{36}$ En doctrina, defienden esta interpretación Chinchón Álvarez, J. "La Convención Internacional para la Protección de todas las Personas contra las Desapariciones Forzadas: nunca es tarde si la dicha es ¿buena?: examen general y perspectivas en España tras la aprobación de la 'Ley de Memoria Histórica'”, Revista de Ciencias Jurídicas y Sociales, $\mathrm{N}^{\circ}$ 7, 2008, p. 31; Ott, L., Enforced Disappearances in International Law, Intersentia, Cambridge-Antwerp-Portland, 2011, pp. 217-219; Scovazzi T./Citroni, G., The Struggle against Enforced Disappearance and the 2007 United Nation Convention, Martinus Nijhoff, Leiden-Boston, 2007, p. 313. Cfr. Corte IDH, Goiburú y otros Vs. Paraguay, Fondo, Reparaciones y Costas. Sentencia de 22 de septiembre de 2006. Serie C N 153 , párr. 83, que adopta la misma interpretación de la CIPPDF en obiter dicta. 


\section{El fraccionamiento conceptual de la desaparición forzada}

Una de las repercusiones más importantes de la categoría de hecho ilícito permanente está vinculada con la activación de la competencia temporal o ratione temporis de los tribunales y órganos internacionales. En el Derecho internacional de los derechos humanos la regla general es que un tribunal u órgano internacional es competente respecto de un Estado a partir de la fecha en que este reconoce la competencia de dicho tribunal u órgano. Esta fecha se denomina "fecha crítica". Los problemas surgen respecto de hechos ilícitos permanentes que hayan comenzado con anterioridad a dicha fecha y cuya comisión se siga realizando con posterioridad a la misma. En ese supuesto, el carácter permanente del hecho ilícito activa la competencia temporal del tribunal $\mathrm{u}$ órgano ${ }^{37}$. Para las desapariciones forzadas rige el mismo principio, con lo que si el ilícito comenzó antes de la fecha crítica y se prolongó con posterioridad a la misma, un tribunal u órgano de supervisión internacional es competente para conocer el hecho ${ }^{38}$.

En el sistema interamericano de derechos humanos la $\mathrm{CADH}$ entra en vigor para cada Estado con el acto de ratificación o adhesión del tratado, acto que se perfecciona mediante el depósito del respectivo instrumento de ratificación o adhesión ${ }^{39}$. La CADH entró en vigencia el 18 de julio de 1978 al depositarse el undécimo instrumento de ratificación. Para esos once Estados, el tratado es obligatorio desde esa fecha. En cambio, para los Estados que se adhirieron o ratificaron el tratado después de su entrada en vigor, la fecha en la que inicia su vigencia es aquella en que efectuaron el depósito del instrumento de ratificación y adhesión ${ }^{40}$.

Sin embargo, para que la Corte sea competente es necesario que el Estado parte de la $\mathrm{CADH}$, en el momento del depósito de su instrumento de ratificación o adhesión o en un momento posterior, declare que reconoce como obligatoria la competencia de la Corte $^{41}$. Por tanto, "la competencia temporal de la Corte está delimitada por el momento en que el Estado haya aceptado dicha competencia" 42 .

Volviendo al tema de las desapariciones forzadas, la Corte IDH ha debido resolver varios casos en que la comisión del ilícito se inició antes de la fecha crítica, continuando con posterioridad. En muchos de esos casos los Estados han impugnado la competencia temporal de la Corte, generalmente, mediante la presentación de excepciones preliminares. Si bien desde su primera sentencia Velásquez Rodríguez vs. Honduras, la Corte ha

${ }^{37}$ Cfr. Aust, A., Modern Treaty Law and Practice. $2^{a}$ ed. Cambridge University Press, Cambridge, 2007, p. 176; Pauwelin, op. cit., pp. 435-436.

${ }^{38}$ Cfr. Scovazzi/Citroni, op. cit., p. 313; Vermeulen, op. cit., p. 190.

${ }^{39} \mathrm{CADH}$, cit., art. 74.2.

${ }^{40}$ Martins, L., "Capítulo IX-Disposiciones comunes", en Steiner, C/Uribe, p. (eds.), Convención Americana sobre Derechos Humanos. Comentario, Konrad Adenauer Stiftung, Berlín-Bogotá, 2014, pp. 931-932

${ }^{41}$ CADH, cit., art. 62.1.

${ }^{42}$ Faúndez Ledesma, H., El sistema interamericano de protección de los derechos humanos. Aspectos institucionales y procesales. $3^{\mathrm{a}}$ ed. Instituto Interamericano de Derechos Humanos, San José de Costa Rica, 2004, p. 627. 
reconocido el carácter permanente de la desaparición forzada en obiter dicta ${ }^{43}$ y ha reafirmado esta tesis en abundante jurisprudencia posterior ${ }^{44}$, los precedentes que merecen un estudio pormenorizado son aquellos en que la desaparición forzada, efectivamente, comenzó antes de la fecha crítica y continuó cometiéndose después.

El primer caso de este tipo fue Blake vs. Guatemala, acerca de las desapariciones de los ciudadanos norteamericanos Nicholas Blake y Griffith Davis, cometidas por la Patrulla de Autodefensa Civil de El Llano. La privación de libertad de Blake ocurrió el 28 de marzo de 1985. Sin embargo, Guatemala reconoció la competencia de la Corte IDH el 9 de marzo de 1987, con la aclaración expresa de que ese reconocimiento se hacía respecto de casos "acaecidos con posterioridad a la fecha en que esta declaración sea presentada" ${ }^{45}$. La Corte se consideró incompetente para pronunciarse respecto de la violación del derecho a la vida (artículo 4 de la CADH) y a la libertad personal (artículo 7 de la $\mathrm{CADH}$ ) de Blake, porque consideró que su detención y muerte se habían producido antes de la fecha crítica y no podían ser calificadas de permanentes ${ }^{46}$. Sin embargo, consideró que era competente para conocer la infracción a las garantías judiciales (artículo 8 de la CADH) en perjuicio de los familiares de Blake, infracción que se había generado debido a la denegación de información por el destino y paradero de la persona desaparecida y que se había prolongado con posterioridad a la fecha crítica hasta el 14 de julio de 1992, fecha en la que se descubrieron los restos mortales ${ }^{47}$. Por tanto, se puede concluir que en opinión de la Corte la denegación de información configura una afectación permanente de las garantías judiciales de los familiares de la persona desaparecida. Sin embargo, el aspecto negativo de esta sentencia estriba en la exclusión de los derechos de las personas desaparecidas de la competencia de la Corte.

Otro caso relevante es Hermanas Serrano Cruz vs. El Salvador, pertinente a la desaparición de dos niñas a manos del ejército salvadoreño. El Estado de El Salvador había formulado una declaración al reconocer la competencia de la Corte IDH, limitándola a hechos posteriores a la fecha de aceptación de dicha competencia ${ }^{48}$. Basados en esta

\footnotetext{
${ }^{43}$ Corte IDH, Velásquez Rodríguez Vs. Honduras. Fondo. Sentencia de 29 de julio de 1988 . Serie C No 4 , párr. 155.

${ }^{44}$ Cfr., v. gr., las siguientes sentencias de la Corte IDH: Godinez Cruz Vs. Honduras, cit., párr. 163; Bámaca Velásquez Vs. Guatemala. Reparaciones y Costas. Sentencia de 22 de febrero de 2002. Serie C No 91 , párr. 128; Gómez Palomino Vs. Perú, cit., párr. 92; Ticona Estrada y otros Vs. Bolivia. Fondo, Reparaciones y Costas. Sentencia de 27 de noviembre de 2008. Serie C No 191, párr. 54.

45 Para el texto de la declaración, vid. en la página web sobre el Estado de Firmas y Ratificaciones de la CADH. Disponible en <http://www.oas.org/dil/esp/tratados_B-32_Convencion_Americana_sobre_Derechos_ Humanos_firmas.htm >. [Consulta: 20 de junio de 2016].

${ }^{46}$ Cfr. Corte IDH. Blake Vs. Guatemala. Excepciones Preliminares. Sentencia de 2 de julio de 1996. Serie C No 27, párrs. 29-33; Corte IDH, Blake Vs. Guatemala. Fondo. Sentencia de 24 de enero de 1998. Serie $\mathrm{C} \mathrm{N}^{\mathrm{0}} 36$, párrs. 82 y 86.

${ }^{47}$ Cfr. Corte IDH. Blake Vs. Guatemala. Excepciones Preliminares, cit., párrs. 33-40; Corte IDH, Blake vs. Guatemala. Fondo, cit., párr. 97.

${ }^{48}$ Estado de Firmas y Ratificaciones de la CADH, cit., El Salvador, Reconocimiento de Competencia, 6 de junio de 1995, punto II: "El Gobierno de El Salvador, al reconocer tal competencia, deja constancia que su aceptación se hace por plazo indefinido, bajo condición de reciprocidad y con la reserva de que los casos en
} 
declaración y repitiendo el criterio del caso Blake, la Corte admitió la excepción de incompetencia ratione temporis respecto de las infracciones al derecho a la vida, a la integridad personal (artículo 5 de la $\mathrm{CADH}$ ) y a la libertad personal, ya que la desaparición de las víctimas se inició en junio de 1982, trece años antes de la fecha de reconocimiento de la competencia, realizado el 6 de junio de $1995^{49}$. En cambio, la Corte solo se declaró competente para el conocimiento de las violaciones a las garantías judiciales y al derecho al recurso (artículos 8 y 25 de la $\mathrm{CADH}$ ) relacionadas con las graves irregularidades que se produjeron durante la substanciación del proceso interno. A juicio de la Corte, dichas infracciones configuraban hechos independientes de la desaparición que se habían producido con posterioridad a la fecha crítica ${ }^{50}$.

Otro caso polémico es Heliodoro Portugal vs. Panamá, por la desaparición de Heliodoro Portugal durante el gobierno militar. En este caso, la víctima fue privada de libertad el 14 de mayo de 1970, fecha muy anterior al reconocimiento de la competencia de la Corte por parte del Estado panameño, formulada el 9 de mayo de $1990^{51}$. Si bien la Corte IDH reconoció la plausibilidad de la noción de hecho ilícito permanente, aceptando que su principal utilidad estriba en activar la competencia temporal de los tribunales internacionales $^{52}$, a renglón seguido y aplicando una argumentación muy polémica, fragmentó la desaparición forzada en un conjunto de infracciones de varios derechos con el fin de valorar si era competente respecto de cada una de ellos. De esa manera, trazó una separación tajante entre la ejecución extrajudicial de la persona desaparecida y su desaparición forzada, declarándose incompetente para conocer la primera, con el argumento que la muerte de la víctima había ocurrido antes de la fecha crítica ${ }^{53}$. Asimismo, se declaró incompetente para el conocimiento de las infracciones a la prohibición de la tortura

que se reconoce la competencia, comprende sola y exclusivamente hechos o actos jurídicos posteriores o hechos o actos jurídicos cuyo principio de ejecución sean posteriores a la fecha del depósito de esta Declaración de Aceptación, reservándose el derecho de hacer cesar la competencia en el momento que lo considere oportuno”.

49 Corte IDH, Hermanas Serrano Cruz Vs. El Salvador. Excepciones Preliminares. Sentencia de 23 de noviembre de 2004. Serie $C^{\circ} \mathrm{N}^{\circ} 118$, párr. 77. Son interesantes las opiniones de algunos autores acerca de la incompatibilidad de este tipo de declaraciones con los fines de la CADH. Cfr. Rivera Juaristi, F. J., "La competencia ratione temporis de la Corte Interamericana en casos de desapariciones forzadas: una crítica del caso Heliodoro Portugal vs. Panamá”, Revista CEJIL, año IV, No 5, diciembre 2009, pp. 28-34; Parayre, S. "La desaparición forzada de personas como violación continuada de los derechos humanos y su incidencia en la determinación de la competencia ratione temporis de la Corte Interamericana de los derechos humanos", Revista del Instituto Interamericano de Derechos Humanos, vol. 29, 1999, p. 61.

${ }^{50}$ Corte IDH, Hermanas Serrano Cruz Vs. El Salvador. Excepciones Preliminares, cit., párrs. 84: "La Corte considera que todos aquellos hechos acaecidos con posterioridad al reconocimiento de la competencia de la Corte por El Salvador referentes a las alegadas violaciones a los artículos 8 y 25 de la Convención, en relación con el artículo 1.1 de la misma, no están excluidos por la limitación realizada por el Estado, puesto que se trata de actuaciones judiciales que constituyen hechos independientes cuyo principio de ejecución es posterior al reconocimiento de la competencia de la Corte por parte de El Salvador, y que podrían configurar violaciones específicas y autónomas de denegación de justicia ocurridas después del reconocimiento de la competencia del Tribunal".

${ }^{51}$ Corte IDH, Heliodoro Portugal Vs. Panamá, cit., párr. 198, párrs. 2 y 26.

52 Ibid., párr. 25.

${ }^{53}$ Ibíd., párrs. 31-32. 
y la libertad de expresión de la persona desaparecida (artículo 13 de la CADH) ${ }^{54}$. Sin embargo, se declaró competente para el conocimiento de la privación de libertad de la persona desaparecida ${ }^{55}$, la afectación a la integridad personal de sus familiares (artículo 5 de la $\mathrm{CADH})^{56}$, la obligación de investigación ${ }^{57}$ y la obligación de tipificación penal de la desaparición forzada ${ }^{58}$. Una lectura detenida de esta sentencia permite deducir varias críticas al enfoque adoptado por la Corte en estas primeras sentencias, así como se reseñará en el siguiente apartado.

\section{Desde el enfoque pluriofensivo al enfoque autónomo de la desaparición forzada}

La posición asumida por la Corte IDH en los precedentes anteriores respecto de la competencia temporal merece algunas críticas. En primer lugar, es obligada una reflexión de las conexiones que existen entre los hechos ilícitos permanentes, la activación de la competencia temporal de los tribunales u órganos internacionales y el principio de irretroactividad de los tratados. En relación con el efecto temporal de los tratados internacionales, la regla general es que estos se aplican desde su entrada en vigor, no pudiendo surtir efectos respecto de hechos acontecidos con anterioridad a ese momento. Sin embargo, los hechos internacionalmente ilícitos permanentes suponen una excepción a esta regla general. Mejor dicho, no se trata de una excepción, sino de instituciones compatibles. En efecto, si un comportamiento de un Estado se ha iniciado antes de la fecha en que un tratado entra en vigencia para ese Estado y continúa desarrollándose con posterioridad a esa fecha, en el evento de que dicho comportamiento suponga una violación al tratado, desde un punto de vista temporal la infracción se produce desde que ha comenzado a existir el tratado para ese Estado. Esta cuestión no supone una infracción al principio de irretroactividad, ya que las disposiciones de un tratado se aplican desde su entrada en vigor a los facta pendentia, es decir, a los hechos que comenzaron con anterioridad a la fecha de vigencia, prolongándose con posterioridad a la misma. Asimismo, esta conclusión es acorde con el principio del efecto inmediato de los tratados, en cuya virtud estos se aplican "inmediatamente" a las partes desde su entrada en vigor ${ }^{59}$. Por tanto y aunque algún autor suponga equívocamente

\footnotetext{
${ }^{54}$ Ibid., párr. 36.

55 Ibid., párr. 37.

56 Ibid., párr. 40.

${ }^{57}$ Ibid., párr. 38.

58 Ibid., párr. 47.
}

${ }^{59}$ Cfr. Aust, op. cit., p. 176; Chinchón Álvarez, J., "Principio de irretroactividad de los tratados, hechos continuados y competencia ratione temporis. Debates pasados, presentes y futuros en el sistema internacional de protección de los derechos humanos", en Torres, S. et al. (coords.), El Derecho Internacional en el mundo multipolar del siglo XXI, Universidad Complutense de Madrid et al., Madrid, 2013, pp. 702-706; Dopagne, F., "1969 Vienna Convention. Article 28. Non-retroactivity of Treaties”, en Corten, O./Pierre, K. (eds.), The Vienna Conventions on the Law of Treaties. A Commentary. 2 vols. Oxford University Press, Oxford, 2011, t. I, pp. 720 y 724. En general, la CDI ha mantenido la misma posición. Cfr. CDI, Tercer Informe sobre el Derecho de los Tratados, por Sir Humphrey Waldock, Relator Especial. Documento A/CN.4/167 y Add.1 a 3, 3 de marzo, 
lo contrario ${ }^{60}$, la activación de la competencia temporal de un tribunal internacional o de un órgano de supervisión respecto de una desaparición forzada iniciada antes de la fecha crítica y continuada con posterioridad no implica una infracción al principio de irretroactividad de los tratados. Esta tesis es perfectamente aplicable a la CADH y a la competencia temporal de la Corte IDH.

Una segunda cuestión a tratar es la tensión que existe entre un enfoque pluriofensivo de la desaparición en relación con un enfoque autónomo. En efecto, la jurisprudencia de los principales tribunales y órganos internacionales de derechos humanos ha concebido tradicionalmente a la desaparición forzada como un hecho ilícito pluriofensivo, esto es, un ilícito que afecta a varios derechos fundamentales, entre ellos, el derecho a la vida, el derecho a la libertad personal entendida como libertad ambulatoria y el derecho a no ser sometido a tortura. Esta concepción ha supuesto una ventaja práctica indiscutible, que ha estribado en otorgar a los tribunales y órganos internacionales un buen fundamento para afirmar su competencia material respecto de casos de desapariciones forzadas, pese a la inexistencia de una regulación específica y autónoma de este ilícito. Así, frente a la ausencia de un derecho humano autónomo a no ser objeto de desaparición forzada que contare con soporte convencional, tribunales y órganos internacionales de supervisión - como la Corte IDH, el Tribunal Europeo de Derechos Humanos o el Comité de Derechos Humanos de Naciones Unidas- han podido conocer casos de desapariciones forzadas gracias al enfoque pluriofensivo, dedicándose a constatar en cada caso si se vulneraban los derechos consagrados en los respectivos tratados internacionales de derechos humanos cuya protección les ha correspondido tutelar.

Sin embargo, este desarrollo fragmentario de la desaparición forzada puede haber incidido negativamente en su consideración como un ilícito autónomo e independiente e incluso puede haber ralentizado la consagración de un derecho humano autónomo a no ser sometido a desaparición ${ }^{61}$. Afortunadamente, el artículo 1 (1) de la CIPPDF vino a

9 de junio, 12 de junio y 7 de julio de 1964, Anuario de la Comisión de Derecho Internacional, 1964, vol. II, p. 10, párr. 5: "El principio de la no retroactividad nunca se viola por aplicar un tratado a cuestiones que se plantean estando el tratado en vigor, aun cuando se iniciaran con anterioridad"; CDI, "Quinto informe sobre la responsabilidad de los Estados, por el Sr. Roberto AgO, Relator Especial. El hecho internacionalmente ilícito del Estado como fuente de responsabilidad internacional. Documento A/CN.4/291 y Add. 1 y 2.22 de marzo, 14 de abril y 4 de mayo de 1976", Anuario de la Comisión de Derecho Internacional, 1976, vol. II(1), p. 23, párr. 62: "Habrá violación de la obligación internacional a que se opone el comportamiento del Estado siempre que, por lo menos durante un cierto período, haya simultaneidad entre la permanencia del hecho del Estado y la existencia a cargo de ese Estado de la obligación de que se trate. Si el comportamiento ha comenzado antes de que la obligación entre en vigor para el Estado y continúa desarrollándose posteriormente, habrá violación de dicha obligación desde el momento en que ésta haya comenzado a existir para el Estado".

${ }^{60}$ Gil Gil, A., "Las aportaciones del Tribunal Europeo de Derechos Humanos al Derecho penal internacional. Coincidencias y diferencias con la Corte Interamericana de Derechos Humanos”, en Steiner, C. (ed.), Sistema interamericano de protección de los derechos humanos y Derecho penal internacional, Konrad Adenauer Stiftung, Berlín-Montevideo-Cuauhtémoc, 2011, pp. 321-323.

${ }^{61}$ Cfr. Comisión de Derechos Humanos. Los derechos civiles y políticos, en particular las cuestiones relacionadas con las desapariciones y las ejecuciones sumarias. Informe presentado por el Sr. Manfred Nowak. E/CN.4/2002/71, 8 de enero de 2002, párrs. 43 y 96; Venturini, G., "International Law and the Offence of Enforced Disappearance", en Venturini, G./Bariatti, S. (eds.), Liber Fausto Pocar. 2 vols. Giuffré, Milano, 2009, t. I, p. 941; Sarkin, J. 
reparar este vacío normativo, consagrando explícitamente el derecho de toda persona a no ser sometida a una desaparición forzada ${ }^{62}$. Pues bien, la plasmación de este derecho debe tener una repercusión práctica, sirviendo de brújula al operador jurídico en la interpretación y aplicación de las obligaciones internacionales concernientes a la desaparición.

En relación con lo anterior, se ha sostenido con razón que la prohibición de la desaparición forzada es una norma de ius cogens ${ }^{63}$. Al respecto, son interesantes y valiosas las aportaciones de Cançado Trindade y Sarkin, quienes fundamentan el carácter de ius cogens de la prohibición de la desaparición en varias características de este ilícito, entre otras, su capacidad para generar impunidad, el carácter absoluto e inderogable del derecho a no ser sometido a desaparición, la procedencia de la jurisdicción universal para perseguir su sanción, su tipificación penal en el Derecho interno de varios Estados, su vinculación con la tortura, su elevada gravedad, la nocividad de sus efectos para la persona desaparecida y sus familiares, la crueldad inherente a sus conductas y la aceptación de su prohibición en la práctica nacional e internacional ${ }^{64}$.

Por tanto, si la prohibición de la desaparición forzada y, a su vez, el derecho humano a no ser sometido a ella, son normas de ius cogens, es posible concluir que se trata de normas jurídicas internacionales con especiales características. Así debe destacarse el carácter imperativo de esas normas, por cuanto todo tratado contrario a las mismas adolecería de nulidad y todo acto de un sujeto internacional que las vulnere no puede ser susceptible de un reconocimiento internacional. Son normas generales, en cuanto manifiestan la concreción de valores fundamentales comunes para toda la comunidad internacional. Generan obligaciones internacionales erga omnes para todos los sujetos del Derecho internacional. Son normas inderogables, en cuanto no pueden ser susceptibles de una modificación basada en la voluntad de los Estados, sino que solo admiten

\footnotetext{
"An Interview with Jeremy Sarkin, Chair-Rapporteur of the United Nations Working Group on Enforced and Involuntary Disappearances, on the Joint Study on Global Practices in Relation to Secret Detention", Essex Human Rights Review, vol. 8, Issue 1, 2011, p. 540.

${ }^{62}$ En efecto, la DPPDF y la CIDF no contemplan este derecho en términos explícitos, limitándose a reconocer el carácter pluriofensivo de la desaparición. Cfr. DPPDF, cit., art. 1; CIDF, cit., Preámbulo, párr. 5.

${ }^{63}$ El derecho a no ser sometido a desaparición forzada ha sido incluido por muchos autores en los listados de derechos humanos que han adquirido el rango de ius cogens. Cfr. Bianchi, A., "Human Rights and the Magic of Jus Cogens", The European Journal of International Law, vol. 19, No 3, 2008, p. 495; Charlesworth, H./Chinkin, C., "The Gender of Jus Cogens", Human Rights Quarterly, vol. 15, Issue 1, 1993, pp. 68 y 70 ; Citroni, G./Scovazzi, T., "Recent Developments in International Law to Combat Enforced Disappearances", Revista Internacional Direito e Cidadania, No 3, Fevereiro 2009, pp. 97 y 110; Fischer-Lescano, A., "Global Constitutional Struggles: Human Rights between colére publique and colère politique”, en Kaleck, W. et al. (eds.), International Prosecution of Human Rights Crimes, Springer, Berlin, 2007, p. 18; Orakhelashvili, A., "State Immunity and Hierarchy of Norms: Why the House of Lords Got It Wrong", The European Journal of International Law, vol. 18, $\mathrm{N}^{\circ}$ 5, 2007, p. 969.

${ }^{64}$ Cfr. Cançado Trindade, A. A., "Enforced Disappearances of Persons as a Violation of Jus Cogens: The Contribution of the Jurisprudence of the Inter-American Court of Human Rights", Nordic Journal of International Law, vol. 81, 2012, pp. 532-536; Sarkin, J., "Why the Prohibition of Enforced Disappearance Has Attained Jus Cogens Status in International Law", Nordic Journal of International Law, vol. 81, 2012, pp. $564-570$ y $574-576$.
} 
una reforma por medio de una norma del mismo carácter ${ }^{65}$. Pues bien, si se pretende guardar coherencia con estas características de las normas de ius cogens, no existe otra alternativa que considerar la desaparición forzada como una noción unitaria, autónoma e independiente, con ello un tratamiento fragmentario de la misma tensionaría de una manera insoportable la naturaleza jurídica de norma ius cogens de su prohibición, vaciándola de su contenido y privándola de su efecto práctico.

Por tanto, aunque la concepción pluriofensiva de este ilícito ha permitido a la Corte adaptar los casos de desapariciones a la dinámica de la $\mathrm{CADH}$, sus disonancias son evidentes con relación a cuestiones tan importantes como la competencia temporal ${ }^{66}$. Lo anterior se demuestra en precedentes como Heliodoro Portugal, que contiene conclusiones rayanas en lo absurdo, ya que la Corte se declaró incompetente respecto del derecho a la vida al presumir que el fallecimiento de la víctima ocurrió antes de la fecha crítica, pero se estimó competente respecto de la privación a la libertad personal sosteniendo que se había prolongado con posterioridad a esa fecha. Si se presta atención a estas afirmaciones, parece ser que la Corte se declara competente para la privación de libertad de personas que presume muertas, conclusión que no puede soportar lógica alguna ${ }^{67}$.

Basado en todo lo anterior, si existe un derecho autónomo a no ser objeto de desaparición forzada con rango de ius cogens, es evidente que la competencia temporal de los tribunales y órganos debe activarse por la desaparición considerada en su integridad.

\section{La consolidación de un enfoque integral de la desaparición forzada}

Afortunadamente, la Corte IDH ha ido modificando su posición originaria respecto del problema de la competencia ratione temporis de la desaparición forzada aplicando en casos más recientes un enfoque unitario. Para demostrar lo anterior, es indispensable remitirse a la sentencia Radilla Pacheco vs. Estados Unidos Mexicanos, sobre la desaparición de un activista social en el estado de Guerrero. En este caso, el Estado mexicano planteó una excepción de incompetencia respecto de la CIDF, invocando una declaración interpretativa formulada junto con la ratificación de ese tratado en que se restringía su aplicación a hechos posteriores a su vigencia ${ }^{68}$. Esta declaración se realizó el 9 de abril de 2002, mientras que la desaparición de Radilla Pacheco ocurrió el 25 de agosto de 1974. Sin embargo, la Corte sostuvo que la interpretación más adecuada de esta declaración

65 Acerca de estas características, vid. Aguilar Cavallo, G., "El reconocimiento jurisprudencial de la tortura y de la desaparición forzada de personas como normas imperativas de Derecho internacional público", Ius et Praxis, vol. 12, N ${ }^{\circ} 1,2006$, pp. 129-134.

${ }^{66}$ Corte IDH, Blake Vs. Guatemala. Fondo, cit., Voto Razonado Cançado Trindade, párr. 15.

${ }^{67}$ Cançado Trindade, "Enforced Disappearances...", cit., p. 510, criticando el fraccionamiento de la desaparición.

${ }^{68}$ Estado de Firmas y Ratificaciones de la CIDF. Disponible en <http://www.oas.org/juridico/spanish/ firmas/a-60.html >. [Consulta: 20 de junio de 2016], México, Declaración interpretativa hecha al momento del depósito del instrumento de ratificación, 9 de abril de 2002: "se entenderá que las disposiciones de dicha Convención se aplicarán a los hechos que constituyan desaparición forzada de personas, se ordenen, ejecuten o cometan con posterioridad a la entrada en vigor de la presente Convención". 
interpretativa debía ser consecuente con la caracterización que la CIDF realiza de la desaparición y con el efecto útil de sus disposiciones. De ese modo, consideró que el tratado era aplicable a desapariciones iniciadas antes de la fecha crítica, pero que continúen o permanezcan más allá de la misma ${ }^{69}$. El aspecto más destacable de este fallo radica en que la Corte asumió una concepción unitaria de la desaparición basándose en la regulación específica de la misma contenida en la CIDF, posición confirmada en jurisprudencia posterior $^{70}$. La adopción de este nuevo enfoque implicó un cambio radical en el análisis sustantivo de los derechos que se consideraron violados por la desaparición forzada. En efecto, la Corte no se limitó a declarar la violación del derecho a la integridad física y de las garantías judiciales de los familiares, sino que se declaró competente para conocer la violación de los derechos a la libertad personal, a la vida, a la integridad personal y al reconocimiento de la personalidad jurídica (artículo 3 de la $\mathrm{CADH}$ ) de la persona desaparecida $^{71}$. De ese modo, se supera el enfoque adoptado por la Corte en su primera etapa jurisprudencial.

Las sentencias posteriores de la Corte han mantenido el mismo enfoque. Una sentencia relevante en ese sentido es Gomes Lund y otros (Guerrilha do Araguaia) vs. Brasil, por la desaparición forzada de varios integrantes de dicha guerrilla. Brasil reconoció la competencia de la Corte el 10 de diciembre de 1998, presentando una declaración en que indicaba que el tribunal solo tendría competencia para conocer de hechos posteriores a dicho reconocimiento ${ }^{72}$. Sin embargo, las desapariciones de los guerrilleros tuvieron lugar entre 1973 y $1974^{73}$. Una vez más, la Corte reconoció el carácter permanente de la desaparición y afirmó su competencia por las desapariciones que persistieron con posterioridad a la fecha crítica ${ }^{74}$. La consecuencia evidente de esta toma de postura fue la declaración de la violación de los derechos a la libertad personal, a la vida, a la integridad personal y al reconocimiento de la personalidad jurídica en perjuicio de los miembros de la guerrilla ${ }^{75}$.

Una sentencia relativamente reciente en que la Corte ha aplicado un enfoque autónomo de la desaparición es Rodríguez Vera y otros (Desaparecidos del Palacio de Justicia)

\footnotetext{
${ }^{69}$ Corte IDH, Radilla Pacheco Vs. Estados Unidos Mexicanos. Excepciones Preliminares, Fondo, Reparaciones y Costas. Sentencia de 23 de noviembre de 2009. Serie C No 209, párr. 31.

${ }^{70}$ Corte IDH, Chitay Nech y otros Vs. Guatemala. Excepciones Preliminares, Fondo, Reparaciones y Costas. Sentencia de 25 de mayo de 2010. Serie C No 212, párrs. 81 y 88.

${ }^{71}$ Corte IDH, Radilla Pacheco Vs. Estados Unidos Mexicanos, cit., párrs. 158-159.

${ }^{72}$ Estado de Firmas y Ratificaciones de la CADH, cit., Brasil, Reconocimiento de Competencia, 10 de diciembre de 1998: "El Gobierno de la República Federativa de Brasil declara que reconoce, por tiempo indeterminado, como obligatoria y de pleno derecho, la competencia de la Corte Interamericana de Derechos Humanos, en todos los casos relacionados con la interpretación o aplicación de la Convención Americana de Derechos Humanos, de conformidad con el artículo 62 de la misma, bajo reserva de reciprocidad y para hechos posteriores a esta Declaración".

73 Corte IDH. Gomes Lund y otros ("Guerrilha do Araguaia") Vs. Brasil. Excepciones Preliminares, Fondo, Reparaciones y Costas. Sentencia de 24 de noviembre de 2010. Serie C No 219, párrs. 88-90.

${ }^{74}$ Ibíd., párrs. 15-19, 101-103 y 110-111.

75 Corte IDH. Gomes Lund y otros ("Guerrilha do Araguaia") Vs. Brasil, cit., párr. 125.
} 
vs. Colombia, por las desapariciones ocurridas en el contexto del asalto al Palacio de Justicia. Este caso es parcialmente distinto de los anteriores, porque el Estado demandado alegaba la incompetencia de la Corte para aplicar la CIDF. Colombia había ratificado ese tratado el 12 de abril de 2005. Sin embargo, los restos de algunas víctimas habían sido identificados con anterioridad a esa fecha, por ello el Estado colombiano alegaba la incompetencia temporal de la Corte para aplicar la CIDF respecto de dichas víctimas. La Corte resolvió que cuando el artículo XIII de la CIDF otorga competencia a la Corte para aplicar el sistema de casos para conocer las infracciones a las obligaciones contraídas en virtud a ese tratado, lo hace respecto de hechos "alegados" como desapariciones. A base de lo anterior, se concluyó que la valoración de un hecho "alegado" como desaparición es un asunto de fondo por el que no corresponde pronunciarse de forma preliminar ${ }^{76}$. Por tanto, no se puede declarar a priori la incompetencia de la Corte sin valorar en el examen de fondo si los hechos corresponden a desapariciones.

Otra sentencia que merece ser analizada es González Medina y Familiares vs. República Dominicana. En este caso, la desaparición de Narciso González Medina se produjo el 26 de mayo de 1994, mientras que el Estado dominicano reconoció la competencia de la Corte el 25 de marzo de 1999. El Estado alegaba que la víctima, al padecer de epilepsia y de un tumor cerebral, no podría haber vivido más de un año en cautiverio, de modo que debía presumirse su muerte en una fecha anterior a la fecha crítica, siendo la Corte incompetente para el conocimiento del caso $^{77}$.

El caso planteaba un problema no analizado hasta el momento y que dice relación con la valoración de la competencia temporal en relación con la fecha presunta de muerte de la víctima. La Corte argumentó que la cesación de la desaparición se produce con la determinación del paradero de la persona desaparecida y con la identificación de sus restos, cuestión que en este caso particular no se había producido ${ }^{78}$. Este caso, por tanto, es interesante para plantear un problema relacionado con la permanencia de la desaparición y que dice relación con la determinación del momento en que se produce la cesación del ilícito. Recuérdese que el cese coincide con la terminación de la conducta denegatoria de información, por esta razón, con el descubrimiento de la información del paradero y situación de la persona desaparecida y con el hallazgo de sus restos mortales ${ }^{79}$. Ahora bien, en la sentencia Ibsen Cárdenas e Ibsen Peña vs. Bolivia, por la desaparición de un estudiante durante la dictadura militar de Hugo Banzer, la Corte fue muy precisa en señalar que no basta el hallazgo de los restos de la víctima para que la desaparición se entienda terminada, sino que es necesaria su adecuada identificación,

\footnotetext{
76 Corte IDH. Rodríguez Vera y otros (Desaparecidos del Palacio de Justicia) Vs. Colombia. Excepciones Preliminares, Fondo, Reparaciones y Costas. Sentencia de 14 de noviembre de 2014. Serie C N ${ }^{\circ} 287$, párrs. 41-44.

${ }^{77}$ Corte IDH. González Medina y Familiares Vs. República Dominicana. Excepciones Preliminares, Fondo, Reparaciones y Costas, Sentencia de 27 de febrero de 2012. Serie C No 240, párr. 42.

${ }^{78}$ Ibid., párrs. 45-52.

${ }^{79}$ Cfr. Corte IDH, Gomes Lund y otros ("Guerrilha do Araguaia") Vs. Brasil, cit., párrs. 103 y 110; Corte IDH, Radilla Pacheco Vs. México, cit., párr. 145.
} 
con lo que "en casos de presunta desaparición forzada en que existan indicios de que la alegada víctima ha fallecido, la determinación de si se ha configurado dicho fenómeno y la cesación del mismo, en su caso, implica, necesariamente, establecer de la manera más fehaciente la identidad del individuo a quien pertenecen los restos recolectados" 80 . Por tanto, como se señala en el caso González Medina y Familiares vs. República Dominicana, incluso si se presumiere el fallecimiento de la víctima, la cesación no se produce, ya que la presunción de muerte solo importa para determinar si se violó el derecho a la $v i_{a}{ }^{81}$. Estas precisiones son de suma relevancia, porque el momento de cesación del ilícito determina el momento hasta el cual la desaparición se sigue cometiendo, lo que es relevante no solo para la activación de la competencia temporal, sino también para identificar el período durante el cual rigen las obligaciones internacionales respecto de la desaparición, particularmente, los deberes de investigar y sancionar.

Ahora bien, si se realiza el ejercicio especulativo de proyectar las consecuencias de este enfoque a la situación de Chile, las conclusiones son evidentes. Chile ratificó la CADH el 10 de agosto de 1990 y reconoció la competencia de la Corte el 21 de agosto del mismo año ${ }^{82}$. Si la Corte sigue manteniendo su posición por la competencia temporal, en el evento de que Chile fuere demandado por la violación de algunos de los derechos consagrados en el sistema interamericano en relación con hechos de desaparición cometida en la época de la dictadura de Pinochet ${ }^{83}$, el argumento de la incompetencia temporal no debería tener ninguna probabilidad de éxito. Chile detenta la responsabilidad internacional de cumplir con las obligaciones generales de respeto, garantía y adecuación del ordenamiento jurídico interno respecto de tales desapariciones hasta que se descubra el destino final de las víctimas. Por tanto, la Corte es temporalmente competente para conocer las eventuales infracciones a estos deberes internacionales. El contexto transicional chileno no está cerrado y no se va a cerrar en un corto o mediano plazo. Desafortunadamente, en la actualidad se siguen produciendo diversos factores de impunidad que infringen las obligaciones antes señaladas, como se documenta exhaustivamente en el reciente informe a cargo de Cath Collins ${ }^{84}$. Más vale la pena insistir: $¡ \mathrm{La}$ Corte IDH es temporalmente competente para conocer eventuales infracciones a las obligaciones impuestas por el sistema interamericano respecto de las desapariciones!

${ }^{80}$ Corte IDH, Ibsen Cárdenas e Ibsen Peña Vs. Bolivia. Fondo, Reparaciones y Costas. Sentencia de 1 de septiembre de 2010. Serie C N 217, párr. 82. Cfr. Corte IDH, La Cantuta Vs. Perú. Fondo, Reparaciones y Costas. Sentencia de 29 de noviembre de 2006. Serie C No 162, párr. 114; Corte IDH, Heliodoro Portugal Vs. Panamá, cit., párr. 34.

${ }^{81}$ Corte IDH, González Medina y Familiares Vs. República Dominicana, cit., párr. 51.

${ }^{82}$ Estado de Firmas y Ratificaciones de la CADH. Disponible en <http://www.oas.org/dil/esp/tratados_B-32_ Convencion_Americana_sobre_Derechos_Humanos_firmas.htm >. [Consulta: 20 de junio de 2016].

${ }^{83}$ Para la documentación de las desapariciones cometidas en la dictadura, vid. Corporación Nacional de Reparación y Conciliación, Informe de la Comisión Nacional de Verdad y Reconciliación, 2 vols., Santiago de Chile, 1991.

${ }^{84}$ Collins, C. "Verdad, justicia, memoria y reparación", en Centro de Derechos Humanos UDP. Informe Anual sobre Derechos Humanos en Chile, Centro de Derechos Humanos, Facultad de Derecho, Universidad Diego Portales, Santiago, 2016, pp. 19-79. 


\section{CONCLUSIONES}

La noción de hecho ilícito permanente es importante en la teoría de la responsabilidad internacional del Estado, ya que proyecta sus repercusiones en varios tópicos, de los que se ha analizado la competencia temporal de los tribunales y órganos internacionales. Ahora bien, es posible afirmar con seguridad que la desaparición forzada es un hecho ilícito permanente, porque su elemento definitorio esencial es una conducta que por sus características se prolonga en el tiempo: la denegación de información.

La revisión de la jurisprudencia de la Corte IDH demuestra que el problema de la permanencia de la desaparición forzada no ha sido abordado de una manera uniforme, pudiendo diferenciarse con claridad dos etapas. En la primera de ellas -que en términos temporales se extiende desde la sentencia Blake pronunciada en 1996, hasta antes de la sentencia Radilla Pacheco del 2009- predomina un enfoque pluriofensivo de la desaparición, que implica su desmembramiento conceptual en varios derechos. Sin embargo, la Corte IDH corrige su posición a partir de la sentencia Radilla Pacheco, un fallo que constituye un punto de inflexión en el tratamiento del problema respecto de la competencia temporal de las desapariciones. Este cambio de criterio se fundamentó en dos líneas argumentales esenciales: la aplicación de la noción de hecho ilícito permanente y la consideración del carácter autónomo de la desaparición. Claramente este es el enfoque que más se adecua a la naturaleza de la desaparición forzada como un ilícito independiente y al carácter de ius cogens de su prohibición y del derecho a no ser sometido a ella.

Julio Cortázar argumentaba que "es imposible enfrentar el hecho de las desapariciones sin que algo en nosotros sienta la presencia de un elemento infrahumano, de una fuerza que parece venir de las profundidades, de esos abismos donde inevitablemente la imaginación termina por situar a todos aquellos que han desaparecido. Si las cosas parecen relativamente explicables en la superficie -los propósitos, los métodos y las consecuencias de las desapariciones-, queda sin embargo un trasfondo irreductible a toda razón, a toda justificación humana" 85 . Una manera para reducir ese abismo de incomprensión y de inhumanidad es activando la competencia de los tribunales internacionales respecto de las desapariciones que se siguen cometiendo en el tiempo pese a su remota iniciación.

\section{BIBLIOGRAFÍA}

\section{Doctrina}

Aguilar Cavallo, G., "El reconocimiento jurisprudencial de la tortura y de la desaparición forzada de personas como normas imperativas de Derecho internacional público", Ius et Praxis, vol. 12, $\mathrm{N}^{\circ} 1,2006$, pp. 117-154.

Ambos, K., Treatise on International Criminal Law: The Crimes and Sentencing, Volume II, Oxford University Press, Oxford, 2013.

${ }^{85}$ Cortázar, J., “Negación del olvido”, Araucaria Chile, Nº 14, 1982, p. 21. 
Andreu-Guzmán, F., "The Draft International Convention on the Protection of All Persons from Forced Disappearance", The Review (International Commission of Jurists), No 62-63, septiembre 2001, pp. 73-106.

Association for the Prevention of Torture. Incommunicado, Unacknowledged and Secret Detention under International Law [En línea], 2 de marzo de 2006. Disponible en <http://www.apt.ch/ en/resources/incommunicado-unacknowledged-and-secret-detention-under-internationallaw-2006/>. [Consulta: 7 de junio de 2016].

Aust, A., Modern Treaty Law and Practice. $2^{\mathrm{a}}$ ed. Cambridge University Press, Cambridge, 2007.

Bianchi, A., "Human Rights and the Magic of Jus Cogens", The European Journal of International Law, vol. 19, $\mathrm{N}^{\circ} 3,2008$, pp. 1110-1115.

Cançado Trindade, A. A., "Enforced Disappearances of Persons as a Violation of Jus Cogens: The Contribution of the Jurisprudence of the Inter-American Court of Human Rights", Nordic Journal of International Law, vol. 81, 2012, pp. 507-536.

Cançado Trindade, A. A., International Law for Humankind. Towards a New Jus Gentium, 2a ed. revisada, Brill-Nijhoff, Leiden-Boston, 2010.

Charlesworth, H./Chinkin, C., "The Gender of Jus Cogens", Human Rights Quarterly, vol. 15, Issue 1, 1993, pp. 63-76.

Chinchón Álvarez, J. "La Convención Internacional para la Protección de todas las Personas contra las Desapariciones Forzadas: nunca es tarde si la dicha es ¿buena?: examen general y perspectivas en España tras la aprobación de la 'Ley de Memoria Histórica'”, Revista de Ciencias Jurídicas y Sociales, $\mathrm{N}^{\circ}$ 7, 2008, pp. 13-55.

Chinchón Álvarez, J., "Principio de irretroactividad de los tratados, hechos continuados y competencia ratione temporis. Debates pasados, presentes y futuros en el sistema internacional de protección de los derechos humanos", en Torres, S. et al. (coords.), El Derecho Internacional en el mundo multipolar del siglo XXI, Universidad Complutense de Madrid et al., Madrid, 2013, pp. 695-711.

Citroni, G./Scovazzi, T., "Recent Developments in International Law to Combat Enforced Disappearances”, Revista Internacional Direito e Cidadania, No 3, Fevereiro 2009, pp. 89-111.

Collins, C. "Verdad, justicia, memoria y reparación", en Centro de Derechos Humanos UDP. Informe Anual sobre Derechos Humanos en Chile, Centro de Derechos Humanos, Facultad de Derecho, Universidad Diego Portales, Santiago, 2016, pp. 19-79.

Cortázar, J., "Negación del olvido", Araucaria Chile, No 14, 1982, pp. 21-23.

CRAWFORD, J., Los artículos de la Comisión de Derecho Internacional sobre la responsabilidad Internacional del estado. Introducción, texto y comentarios. Introducción y apéndices traducidos por L. Fonseca, bajo la supervisión de C. Espósito. Dykinson, Madrid, 2004.

David, E., "Primary and Secondary Rules", en Crawford, J./Pellet, A./Olleson, S. (eds.), The Law of International Responsibility, Oxford University Press, Oxford, 2010, pp. 27-33.

Dopagne, F., “1969 Vienna Convention. Article 28. Non-retroactivity of Treaties”, en Corten, O./Pierre, K. (eds.), The Vienna Conventions on the Law of Treaties. A Commentary. 2 vols. Oxford University Press, Oxford, 2011, t. I, pp. 718-728.

Espósıto, A./Gentile, G./Traspasso, M. T., "I crimini contro l' umanitá", en Lattanzi, G./Monetti, V. (coords.). La Corte Penale Internazionale. Organi-Competenza-Reati-Processo. Giuffré, Milano, 2006, pp. 6-33.

FAúndez Ledesma, H., El sistema interamericano de protección de los derechos humanos. Aspectos institucionales y procesales. $3^{\mathrm{a}}$ ed. Instituto Interamericano de Derechos Humanos, San José de Costa Rica, 2004. 
Fischer-Lescano, A. "Global Constitutional Struggles: Human Rights between colére publique and colère politique", en Kaleck, W. et al. (eds.), International Prosecution of Human Rights Crimes, Springer, Berlin, 2007, pp. 13-27.

Gil Gil, A., "Las aportaciones del Tribunal Europeo de Derechos Humanos al Derecho penal internacional. Coincidencias y diferencias con la Corte Interamericana de Derechos Humanos", en Steiner, C. (ed.), Sistema interamericano de protección de los derechos humanos y Derecho penal internacional, Konrad Adenauer Stiftung, Berlín-Montevideo-Cuauhtémoc, 2011, pp. 311-344.

Kyriakou, N., "Enforced Disappearances in Cyprus: Problems and Prospects of the Case Law of the European Court of Human Rights", European Human Rights Law Review, vol. 2, 2011, pp. 190-199.

Mariño Menéndez, F., Derecho Internacional Público. Parte General. 4ª ed., Trotta, Madrid, 2005.

Martins, L., "Capítulo IX-Disposiciones comunes", en Steiner, C/Uribe, P. (eds.), Convención Americana sobre Derechos Humanos. Comentario, Konrad Adenauer Stiftung, Berlín-Bogotá, 2014, pp. 914-926.

Orakhelashvili, A., "State Immunity and Hierarchy of Norms: Why the House of Lords Got It Wrong”, The European Journal of International Law, vol. 18, No 5, 2007, pp. 955-970.

OTт, L., Enforced Disappearances in International Law, Intersentia, Cambridge-Antwerp-Portland, 2011.

Parayre, S. "La desaparición forzada de personas como violación continuada de los derechos humanos y su incidencia en la determinación de la competencia ratione temporis de la Corte Interamericana de los derechos humanos", Revista del Instituto Interamericano de Derechos Humanos, vol. 29, 1999, pp. 25-67.

Pauwelin, J. "The Concept of a 'Continuing Violation' of an International Obligation: Selected Problems”, British Yearbook of International Law, vol. 66 (1), 1995, pp. 415-450.

Pellet, A., "The ILC'S Articles on State Responsibility for Internationally Wrongful Acts and Related Texts", en Crawford, J./Pellet, A./Olleson, S. (eds.), The Law of International Responsibility, Oxford University Press, Oxford, 2010, pp. 75-94.

PÉrez Solla, M. F., Enforced Disappearances in International Human Rights, McFarland \& Company, Jefferson, 2006.

Rivera Juaristi, F. J., "La competencia ratione temporis de la Corte Interamericana en casos de desapariciones forzadas: una crítica del caso Heliodoro Portugal vs. Panamá”, Revista CEJIL, año IV, $\mathrm{N}^{\circ}$ 5, diciembre 2009, pp. 20-37.

Robinson, D., "Defining 'Crimes against Humanity' at the Rome Conference”, American Journal of International Law, 93/1(1999), pp. 43-57.

Rodley, N./Pollard, M., The Treatment of Prisoners under International Law. $3^{\text {a }}$ ed. Oxford University Press, Oxford, 2009.

Salmon, J. "Duration of the Breach", en Crawford, J./Pellet, A./Olleson, S. (eds.), The Law of International Responsibility, Oxford University Press, Oxford, 2010, pp. 383-396.

SARKIN, J. "An Interview with Jeremy Sarkin, Chair-Rapporteur of the United Nations Working Group on Enforced and Involuntary Disappearances, on the Joint Study on Global Practices in Relation to Secret Detention”, Essex Human Rights Review, vol. 8, Issue 1, 2011, pp. 57-67.

Sarkin, J., "Why the Prohibition of Enforced Disappearance Has Attained Jus Cogens Status in International Law”, Nordic Journal of International Law, vol. 81, 2012, pp. 537-583.

Scovazzi T./Citroni, G., The Struggle against Enforced Disappearance and the 2007 United Nation Convention, Martinus Nijhoff, Leiden-Boston, 2007.

Sferrazza Taibi, P., "Desaparición forzada", Eunomia, Nº 8, marzo-agosto 2015, pp. 160-170. 
Stern, B., "The Elements of an Internationally Wrongful Act”, en Crawford, J./Pellet, A./ Olleson, S. (eds.), The Law of International Responsibility, Oxford University Press, Oxford, 2010, pp. 193-220.

Venturini, G., "International Law and the Offence of Enforced Disappearance", en Venturini, G./Bariatti, S. (eds.), Liber Fausto Pocar. 2 vols. Giuffré, Milano, 2009, t. I, pp. 939-954.

Vermeulen, M. L., Enforced Disappearance. Determining State Responsibility under the International Convention for the Protection of All Persons from Enforced Disappearance, Intersentia, Cambridge et al., 2012.

Werle, G., Tratado de Derecho Penal Internacional. $2^{\mathrm{a}}$ ed. Traducción de C. Cárdenas Aravena, J. Couso Salas y M. Gutiérrez Rodríguez (trads.). Tirant lo Blanch, Valencia, 2011.

Informes, resoluciones y otros documentos de órganos internacionales

AG, Ejecuciones extrajudiciales, sumarias o arbitrarias. Informe provisional sobre la situación mundial con respecto a las ejecuciones extrajudiciales, sumarias o arbitrarias presentado por Philip Alston, Relator Especial. A/61/311, 5 de septiembre de 2006.

AG, Responsabilidad del Estado por Hechos Internacionalmente Ilícitos, res. 56/83, 12 de diciembre de 2001.

CDI, "Draft articles on State responsibility. 1. Text of the Draft Articles Provisionally Adopted by the Commission on First Reading", Yearbook of the International Law Commission, 1996, vol. II(2), pp. 58-73.

CDI, Proyecto de artículos sobre responsabilidad internacional del Estado, en CDI, Informe de la Comisión de Derecho Internacional, $53^{\circ}$ período de sesiones (23 de abril a $1^{\circ}$ de junio y 2 de julio a 10 de agosto de 2001), A/56/10, pp. 21-405.

CDI, "Quinto informe sobre la responsabilidad de los Estados, por el Sr. Roberto AGo, Relator Especial. El hecho internacionalmente ilícito del Estado como fuente de responsabilidad internacional. Documento A/CN.4/291 y Add. 1 y 2. 22 de marzo, 14 de abril y 4 de mayo de 1976", Anuario de la Comisión de Derecho Internacional, 1976, vol. II(1), pp. 3-59.

CDI, Tercer Informe sobre el Derecho de los Tratados, por Sir Humphrey Waldock, Relator Especial. Documento A/CN.4/167 y Add.1 a 3, 3 de marzo, 9 de junio, 12 de junio y 7 de julio de 1964, Anuario de la Comisión de Derecho Internacional, 1964, vol. II, pp. 3-63.

Comisión de Derechos Humanos. Los derechos civiles y políticos, en particular las cuestiones relacionadas con las desapariciones y las ejecuciones sumarias. Informe presentado por el Sr. Manfred Nowak. E/CN.4/2002/71, 8 de enero de 2002.

\section{Jurisprudencia}

Comité de Derechos Humanos, Yasoda Sharma vs. Nepal, comunicación No 1469/2006, 28 de octubre de 2008.

Comité de Derechos Humanos, Zobra Madoui vs. Algeria, comunicación No 1495/2006, 28 de octubre de 2008.

Corte IDH, Bámaca Velásquez Vs. Guatemala. Reparaciones y Costas. Sentencia de 22 de febrero de 2002. Serie $C \mathrm{~N}^{\circ} 91$.

Corte IDH, Blake Vs. Guatemala. Excepciones Preliminares. Sentencia de 2 de julio de 1996. Serie $\mathrm{C} \mathrm{N}^{\circ} 27$.

Corte IDH, Blake Vs. Guatemala. Fondo. Sentencia de 24 de enero de 1998. Serie C No 36. 
Corte IDH, Chitay Nech y otros Vs. Guatemala. Excepciones Preliminares, Fondo, Reparaciones y Costas. Sentencia de 25 de mayo de 2010. Serie C N 212.

Corte IDH, Fairén Garbi y Solís Corrales Vs. Honduras. Fondo. Sentencia de 15 de marzo de 1989. Serie C No 6.

Corte IDH, Godínez Cruz Vs. Honduras. Fondo. Sentencia de 20 de enero de 1989. Serie C No 5.

Corte IDH, Goiburú y otros Vs. Paraguay, Fondo, Reparaciones y Costas. Sentencia de 22 de septiembre de 2006. Serie C No 153.

Corte IDH, Gomes Lund y otros ("Guerrilha do Araguaia") Vs. Brasil. Excepciones Preliminares, Fondo, Reparaciones y Costas. Sentencia de 24 de noviembre de 2010. Serie C No 219.

Conte IDH, Gómez Palomino Vs. Perú. Fondo, Reparaciones y Costas. Sentencia de 22 de noviembre de 2005. Serie C No 136.

Corte IDH, Heliodoro Portugal Vs. Panamá. Excepciones Preliminares, Fondo, Reparaciones y Costas. Sentencia de 12 de agosto de 2008. Serie C No 186.

Conte IDH, Hermanas Serrano Cruz Vs. El Salvador. Excepciones Preliminares. Sentencia de 23 de noviembre de 2004. Serie C No 118.

Corte IDH, Radilla Pacheco Vs. México. Excepciones Preliminares, Fondo, Reparaciones y Costas. Sentencia de 23 de noviembre de 2009. Serie C No 209.

Corte IDH, Radilla Pacheco Vs. Estados Unidos Mexicanos. Excepciones Preliminares, Fondo, Reparaciones y Costas. Sentencia de 23 de noviembre de 2009. Serie C No 209.

Corte IDH, Ticona Estrada y otros Vs. Bolivia. Fondo, Reparaciones y Costas. Sentencia de 27 de noviembre de 2008. Serie C No 191.

CORTE Internacional de Justicia, United States Diplomatic and Consular Staff in Tehran, judgment, 24 de mayo de 1980, I.C.J. Reports, 1980, pp. 3-46.

Tribunal Europeo de Derechos Humanos, Kurt Vs. Turkey, judgment (15/1997/799/1002), 25 de mayo de 1998. 
